\title{
$\mathrm{PP}-\mathrm{SEBS} /$ 실리케이트 복합체의 유변학적 특성 연구
}

\author{
김연철1* \\ ${ }^{1}$ 공주대학교 신소재공학부 고분자공학전공
}

\section{Study on the rheological properties of PP-SEBS/silicate composites}

\author{
Youn Cheol Kim ${ }^{1 *}$ \\ ${ }^{1}$ Major in Polymer Science \& Engineering, Kongju National University, \\ 275 Budae-dong, Cheonan 330-717, Korea
}

요 약 폴리프로필렌(polypropylene, PP)-SEBS(styrene-ethylene/butylene-styrene triblock copolymer)/실리케이트 복합체 를 $\mathrm{PP}$ 의 조성을 35,40 그리고 $45 \mathrm{wt} \%$ 로 변화시키며 실험실 규모의 Brabender Mixer를 이용하여 $200^{\circ} \mathrm{C}$ 에서 용융상태 에서 제조하였다. 실리케이트 조성은 $5 \mathrm{wt} \%$ 로 고정하였다. $\mathrm{PP}-\mathrm{SEBS} /$ 실리케이트 복합체의 열적특성을 $\mathrm{DSC}$ 와 TGA를 이용하여 분석하였다. PP-SEBS 콤파운드의 용융온도는 SEBS 함량에 따라 $141^{\circ} \mathrm{C}$ 까지 감소하였다. 실리케이트가 $\mathrm{PP}-\mathrm{SEBS}$ 에 첨가되었을 때 분해온도가 증가하는 것을 TGA 결과로부터 확인할 수 있었다. 콤파운드의 유변학적 특성 을 동적유변측정기를 이용하여 측정하였다. PP-SEBS/실리케이트 복합체는 PP-SEBS 콤파운드보다 shear thinning과 탄 성특성이 증가하였다. 탄성특성 증가를 확인하기 위해 Van Gurp-Palmen 분석을 이용하였다.

\begin{abstract}
Polypropylene (PP)-SEBS/silicate composites with PP content of 35, 40, and $45 \mathrm{wt} \%$ were fabricated by melt compounding at $200^{\circ} \mathrm{C}$, using lab scale Brabender mixer. The content of silicate was fixed at $5 \mathrm{wt} \%$. The thermal properties of the PP-SEBS/silicate composites were investigated by differential scanning calorimetry (DSC) and thermogravimetric analyzer (TGA). The melting temperature of PP-SEBS compound decreased up to $141^{\circ} \mathrm{C}$ with SEBS content. TGA result indicates an increase in degradation temperature when the silicate was added in the PP-SEBS compound. The rheological properties of the compounds were measured by dynamic Rheometer. PP-SEBS/silicate composite indicates higher shear thinning and elastic property than PP-SEBS compound. Van Gurp-Palmen analysis was applied in order to certify an increase in elasticity.
\end{abstract}

Key Words : Polypropylene, SEBS, Silicate, Rheological Properties

\section{1. 서론}

친환경, 고연비로 소재 패러다임이 변화됨에 따라 자 동차용 소재의 플라스틱 채용이 증가하고 있는 추세에 있고, 환경규제 강화에 따라서 적용 소재의 재활용에 대 한 기술 개발이 활발히 진행되고 있으며, 실제로 $\mathrm{EU}$ 를 중심으로 재활용에 대한 법규를 강화하고 있다. 자동차용 고분자재료의 재활용성을 높이기 위한 소재변경 및 구조 개선의 일환으로 $\mathrm{PU}$ 대신 올레핀계인 $\mathrm{PP}$ 폼을 개발하려 는 시도가 있었지만, $\mathrm{PP}$ 폼은 기존 $\mathrm{PU}$ 폼 대비 쿠션성이 많이 떨어지므로 Main Seat Cover에는 적용되지 못하고
있고 Door Trim이나 Head Linner 등과의 라미네이팅에 일부 적용되고 있는 중이다. 쿠션성의 문제를 개선하기 위한 한 방법으로 열적가공이 가능하면서도 탄성을 보이 는 PP계 열가소성 엘라스토머(Thermoplastic elastomer, $\mathrm{TPE}$ ) 적용을 들 수 있는데, 그러나 PP계 TPE의 경우 용 융장력(melt tension)이 PU나 폴리스티렌(polystyrene, PS) 대비 열세하기 때문에 발포거동 및 물성이 요구수준을 만족시키지 않아 실제 적용 분야에제약을 받고 있다[1].

$\mathrm{PP}$ 의 용융장력은 분자량분포도(bimodal type)와 장쇄 분지(LCB)에 크게 영향을 받는 것으로 알려져 있고, 이 는 분자량이 다른 두 종류의 $\mathrm{PP}$ 를 블렌드하거나 전자선

이 논문은 2010년도 정부(교육과학기술부)의 재원으로 한국연구재단의 지원을 받아 수행된 연구임 (No. 2010-0022015).

*교신저자 : 김연철(younkim@kongju.ac.kr)

접수일 11년 02월 21일수정일 11년 04월 05일

게재확정일 11년 04월 07일 
가교 등에 의해 장쇄분지를 도입하여 해결하려는 시도들 이 연구되어 왔다[2-4]. 또한 고분자 소재에 무기물인 실 리케이트 소량을 나노 크기로 분산시켜 복합체를 형성하 면 유변학적 특성에 많은 영향을 주는 연구결과들이 발 표되어 왔고, 최적의 물성을 위해서는 실리케이트의 분산 성이 매우 중요한 인자로 고려되고 있다

나노복합체는 한 구성 성분이 나노 크기로 분산된 물 질을 말하는데, 이러한 분산특성으로 인해 기존의 마이크 로 단위의 분산상을 가진 복합체와 매우 다른 독특한 물 성을 보이고 있으며, 주로 유기/무기 혼성복합체에 대한 연구가 그 주류를 이루고 있다. 폴리프로필렌(PP)은 다양 한 분야에 널리 이용되고 있는 대표적인 범용수지로서 경제성과 우수한 물성으로 인해 많은 연구가 진행되고 있으며, 실리케이트와의 나노복합체에 대한 연구가 일본 의 도요타 등을 중심으로 활발히 진행되어 왔다[5-7].

고분자 재료의 유변학적 특성은 고분자 재료의 성형가 공시 중요한 변수중 하나일 뿐만아니라 낮은 전단영역에 서의 용융점도로부터 용융장력의 정도를 유추할 수 있기 때문에 많은 연구들이 진행되어 왔다[8-13]. 이들 연구 결 과를 요약해 보면, 고분자/실리케이트 나노복합체에서 실 리케이트의 분산이나 계면접착특성이 좋아지면 용융상태 에서 실리케이트에 의한 고체특성이 고분자 용융체에 영 향을 미쳐 용융점도에 있어서 shear thinning 효과가 두드 러지게 나타나고, 낮은 전단영역에서의 용융점도가 큰 폭 으로 증가하는 결과들로 요약할 수 있다.

따라서 본 연구에서는 PP-SEBS에 실리케이트를 Brabender Mixer를 이용하여 복합체를 제조하고 복합체 의 유변학적 특성을 평가하여, 실리케이트의 첨가가 PP-SEBS 열가소성 엘라스토머의 유변학적 특성에 미치 는 영향을 고찰하고자 한다.

\section{2. 실험}

\section{1 실험재료}

실험에 사용된 랜덤 폴리프로필렌(PP)은 용융지수는 $1.1 \mathrm{~g} / 10 \mathrm{~min}$ 이고 용융온도 $154^{\circ} \mathrm{C}$ 인 호남석유화학 제품을 $\mathrm{SEBS}$ 는 스티렌이 $30 \mathrm{wt} \%$ 인 제품을 사용하였다. 층상 실 리케이트는 미국 Southern clay사의 $20 \mathrm{~A}$ 제품을 사용하 였다. Oil은 paraffinic and naphthanic hydrocarbon을 포함 하는 지방족 미네랄 오일을 사용하였다.

\section{2 실험방법}

2.2.1 PP-SEBS/실리케이트 복합체의 제조
실리케이트 양을 $5 \mathrm{wt} \%$ 로 고정한 후 펠렛 상태의 $\mathrm{PP}$ 에 $\mathrm{SEBS} / \mathrm{Oil}$ 의 함량을 Table 1 의 조성으로 혼합하고 $200^{\circ} \mathrm{C}$ 의 Brabender mixer에서 50rpm 의 스크류 속도로 5 분 동 안 혼련하여 PP-SEBS/실리케이트 복합체를 제조하였다. 경도 조절을 위한 Oil은 SEBS와 동량을 사용하였다.

\section{2 .2 측정}

화학구조 분석을 위한 적외선분광기(FT-IR)는 Bomen-MB-100 을 이용하여 $400-4,000 \mathrm{~cm}^{-1}$, 파수 범 위에서 스캔수는 16 으로 실험을 수행하였다. 시차주사열 용량분석기(DSC)와 열중량분석기(TGA)의 측정은 $\mathrm{TA}$ Instruments DSC 10 을 이용하였으며, 승온속도는 $20^{\circ} \mathrm{C}$ $/ \mathrm{min}$ 로 고정하였다. 모든 열분석은 질소분위기하에서 수 행하였다. 유변학적 특성을 측정하기 위해서 동적 유변측 정기를 사용하였다. 동적 유변측정기는 Anton Parr사의 $\mathrm{ARES}$ 를 사용하여, strain 10, 주파수 $0.05-500 \mathrm{~Hz}$, Gap size $1.0 \mathrm{~mm}$ 의 조건으로 $180^{\circ} \mathrm{C}$ 에서 측정하였다. 직경 $25 \mathrm{~mm}$ 의 parallel plate를 사용하여 실험을 수행하였다. 시 편은 $180^{\circ} \mathrm{C}$ 가열프레스를 이용하여 제작하였고, 시료를 $100^{\circ} \mathrm{C}$ 진공오븐에서 10 시간 이상 건조 후 사용하였다.

\section{3. 결과 및 고찰}

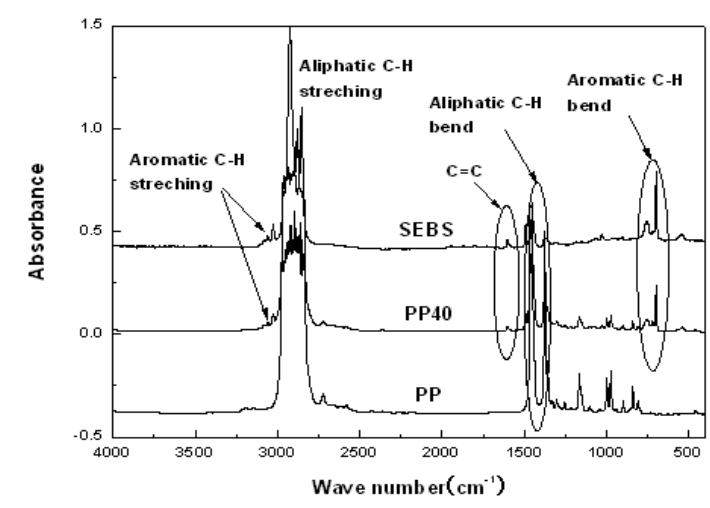

[그림 1] PP, SEBS, PP40의 FT-IR 스펙트럼

그림 1은 PP, SEBS 그리고 PP40의 FT-IR 스펙트럼을 보여주는 것이다. PP와 SEBS의 FT-IR 스펙트럼에서 가 장 큰 차이점은 $1,600 \mathrm{~cm}^{-1}$ 근처에서 나타나는 스티렌과 부타디엔의 $\mathrm{C}=\mathrm{H}$ 신축진동과 $700 \mathrm{~cm}^{-1}$ 근처에서 나타나는 스티렌의 방향족 C-H 피이크 등 이다. PP-SEBS 콤파운 드인 $\mathrm{PP} 40$ 의 적외선 스펙트럼에서 $\mathrm{PP}$ 에서 나타나는 피 이크와 함께 $\mathrm{SEBS}$ 의 스티렌의 방향족 $\mathrm{C}=\mathrm{C}$ 와 $\mathrm{C}-\mathrm{H}$ 피이 
크를 보여주기 때문에 PP-SEBS 콤파운드가 제조된 것을 확인할 수 있었다.

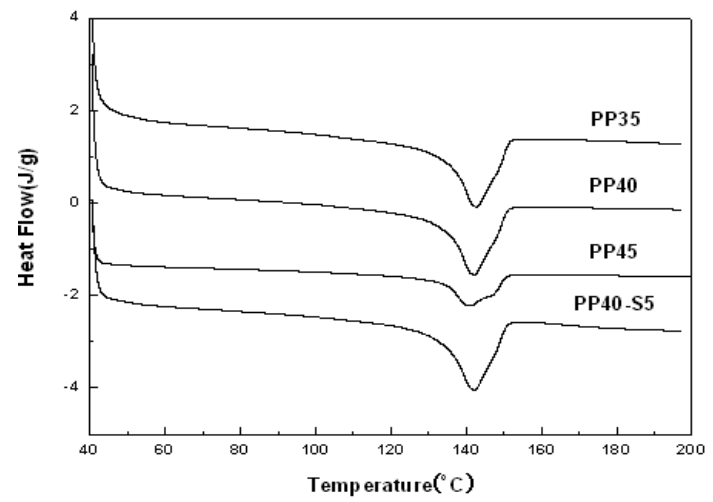

(a)

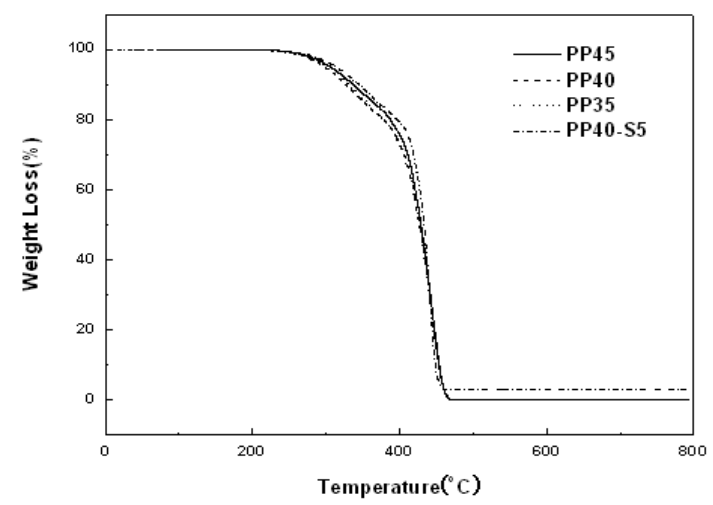

(b)

[그림 2] PP-SEBS/실리케이트 복합체의 DSC (a)와 TGA (b) 곡선

그림 2는 SEBS 함량에 따른 $\mathrm{DSC}$ 와 TGA 실험결과를 보여주는 것이다. PP-SEBS의 경우 용융온도가 대략 $141-146^{\circ} \mathrm{C}$ 의 값을 나타내고 있고, SEBS 함량이 증가함에 따라 용융온도는 감소하였으며, 실리케이트가 첨가된 경 우 $3{ }^{\circ} \mathrm{C}$ 정도 증가된 값을 나타내었다. $\mathrm{TGA}$ 곡선에서 $3 \mathrm{wt} \%$ 중량감소가 일어나는 온도는 $\mathrm{SEBS}$ 의 함량이 증가 할 때 $391{ }^{\circ} \mathrm{C}$ 에서 $364^{\circ} \mathrm{C}$ 까지 큰 폭으로 감소하였고, 이는 열적특성이 열세한 SEBS의 함량 증가에 기인한 것으로 설명될 수 있다. 또한 실리케이트를 처방하지 않은 시료 와 비교하였을 때 실리케이트가 처방된 시료의 분해온도 가 약 $20^{\circ} \mathrm{C}$ 의 증가를 보여주었다. 이와 같은 분해온도의 증가는 PP-SEBS 매트릭스내에 실리케이트가 분산되면 서 나타나는 현상으로 해석할 수 있다. SEBS 함량에 따 른 시료의 열적 특성을 표 1 에 정리하였다.

PP-SEBS에 대한 실리케이트 첨가에 대한 영향을 보
다 자세히 살펴보기 위해 유변학적 특성을 측정하였다. 고분자 매트릭스내에 실리케이트와 같은 고형 첨가제가 첨가되면 zero shear viscosity 값이 뉴토니언 거동에서 비 뉴토니언 거동으로 바뀌게 되고 이와 같은 거동은 첨가 제의 분산성이 우수할수록 두드러지게 나타나는 것으로 알려져 있다.

그림 3은 이들 PP-SEBS와 실리케이트 복합체의 복합 점도(complex viscosity)를 보여주는 것이다. 우선 SEBS 함량이 증가함에 따라

[표 1] PP-SEBS/실리케이트 복합체의 기초특성과 power law index

\begin{tabular}{|c|c|c|c|c|}
\hline Samples & Content & $\begin{array}{c}\mathrm{T}_{\mathrm{m}} \\
\left({ }^{\circ} \mathrm{C}\right)\end{array}$ & $\begin{array}{c}\mathrm{T}_{\mathrm{d}} \\
\left({ }^{\circ} \mathrm{C}\right)\end{array}$ & $\mathrm{n}$ \\
\hline PP45 & PP45-SEBS27.5-Oil27.5 & 146 & 391 & 0.65 \\
\hline PP40 & PP40-SEBS30-Oil30 & 142 & 384 & 0.60 \\
\hline PP35 & PP35-SEBS32.5-Oil32.5 & 141 & 364 & 0.55 \\
\hline PP40-S5 & PP37-SEBS29-Oil29-S5 & 145 & 406 & 0.37 \\
\hline
\end{tabular}

* $\mathrm{T}_{\mathrm{m}}$ : melting temp., $\mathrm{T}_{\mathrm{d}}$ : temp. at $3 \mathrm{wt} \%$ loss

** $\mathrm{n}$ : indexes were calculated by power law, $\eta=m\left(\right.$ frequency) ${ }^{\mathrm{n}-1}$

$* * * S$ : silicate

PP-SEBS의 복합점도가 증가하는 것을 볼 수 있다. 이 는 SEBS가 고무특성을 나타내기 때문에 점도가 높은 것 으로 판단된다. 다음으로 실리케이트가 첨가된 PP40-S5 를 PP40과 비교하였을 때 낮은 영역에서의 복합점도(즉 zero shear viscosity) 값이 크게 증가하는 것을 볼 수 있 다. 또한 주파수(frequency)에 따른 복합점도 변화에 대한 기울기를 의미하는 shear thinning effect가 크게 증가하고 있음을 알 수 있다.

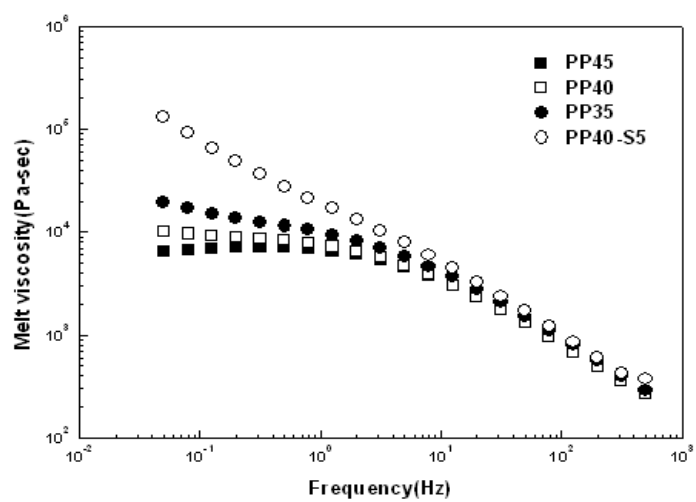

[그림 3] PP-SEBS/실리케이트 복합체의 복합점도.

이와 같은 shear thinning effect는 첨가된 실리케이트 
의 고체특성이 고분자 용융체에 영향을 주어 나타나는 것으로 해석할 수 있고, $\mathrm{PP}$ 의 용융장력 증가와 밀접한 연 관이 있다. Shear thinning effect를 자세히 살펴보기 위해 주파수가 $0.05 \mathrm{~Hz}$ 에서의 복합점도로 나눈 점도를 그림 4 에 나타내었다. 그림에서 볼 수 있듯이 SEBS의 함량이 증가할수록 기울기가 급해지는 것을 볼 수 있다. 이와 같 은 기울기의 정도로부터 shear thinning 현상을 파악하게 되는데 이때 사용하는 변수가 power law index (n)이다. Power law index가 1에 가까울수록 뉴톤거동을 zero에 가 까울수록 비뉴톤 거동을 의미하는 것이다. Power law index는 그림 4 의 실선과 같이 회귀분석을 통하여 계산하 였고, 표 1에 정리하였다. Power law index의 값이 SEBS 의 함량에 따라 감소하는 것을 볼 수 있고, 실리케이트가 포함된 경우 0.371 까지 매우 큰 폭으로 감소하고 있음을 알 수 있다.

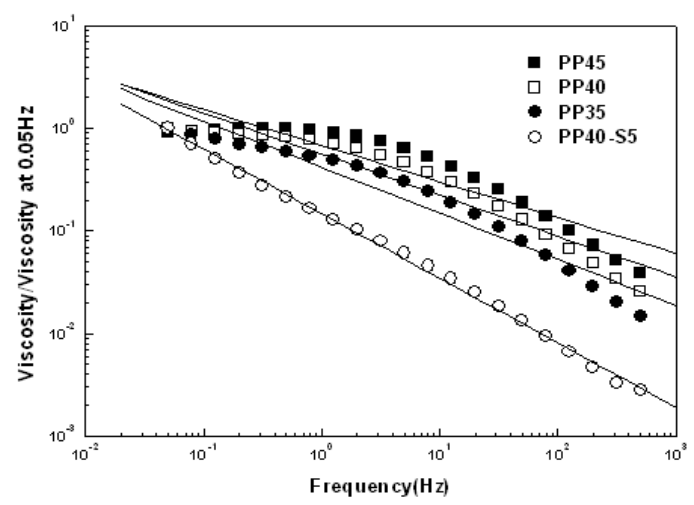

[그림 4] PP-SEBS/실리케이트 복합체의 $\mathrm{n}^{*} / \mathrm{n}^{*}{ }_{0.05 \mathrm{~Hz}}$

낮은 영역에서의 복합점도 증가는 탄성의 증가를 의미 하며 이는 용융상태에서의 장력인 용융장력의 증가를 의 미하는 것이다. 이들 복합체의 탄성과 점성특성에 대한 실리케이트 첨가 영향을 보다 자세하게 고찰하기 위해 탄성을 나타내는 저장탄성률 $\left(\mathrm{G}^{\prime}\right)$ 과 점성을 나타내는 손실 탄성률 $\left(\mathrm{G}^{\prime \prime}\right)$ 을 그림 5 에 도시하였다. 실리케이트가 첨가 된 시료의 저장탄성률이 상대적으로 큰 폭으로 증가하고 있음을 알 수 있고, 이는 실리케이트가 첨가되어 고체 특 성을 나타내어 탄성을 증가시킨 때문으로 해석할 수 있 다.

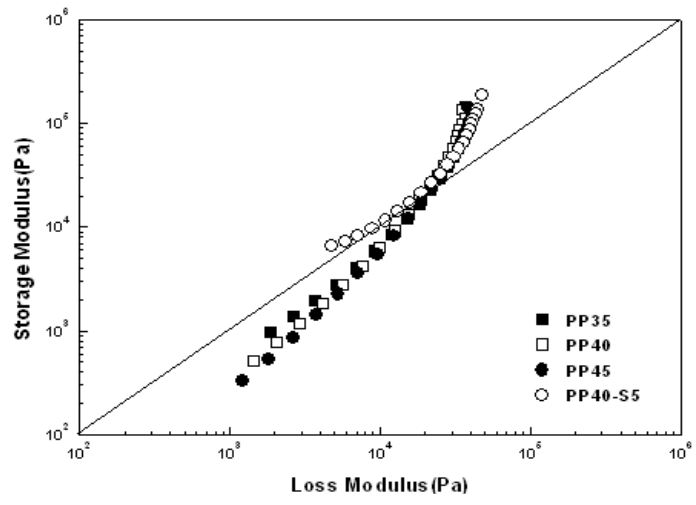

[그림 5] PP-SEBS/실리케이트 복합체의 G'- G" 그래프

PP-SEBS 대비 PP-SEBS/실리케이트 복합체의 탄성 특 성 변화를 보다 자세히 관찰하기 위해 폴리올레핀에서 주로 사용하는 Van Gurp-Palmen 분석[8]을 사용하였다. 제조한 복합체들의 Van Gurp-Palmen 분석 결과를 살펴 보기 위해 복합탄성률과 위상차( $($ )를 계산하여 그림 6 에 나타내었다.

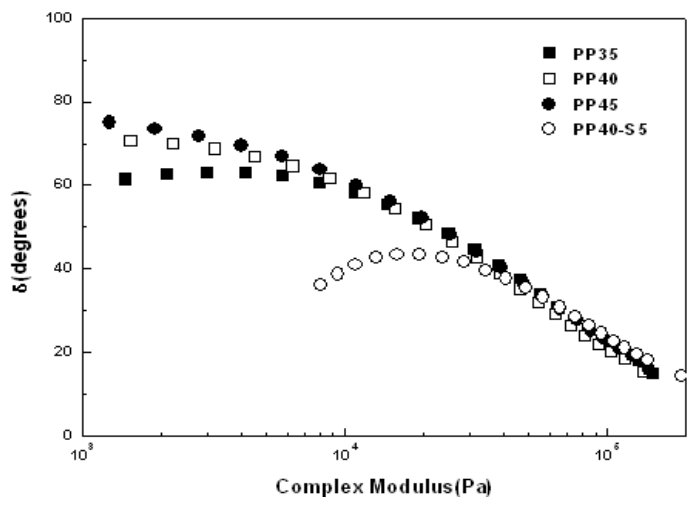

[그림 6] PP-SEBS/실리케이트 복합체의 Van Gurp-Palmen 분석

PP-SEBS 콤파운드들의 곡선 형태가 대부분 유사하게 나타나는 것을 확인할 수 있는 반면 실리케이트가 첨가 된 PP-SEBS/실리케이트 복합체의 위상차 곡선 형태는 크게 차이가 나는 것을 알 수 있다. 위상차 값 또한 PP-SEBS 콤파운드들 보다 낮은 값을 보여주고 있는데 이는 PP-SEBS/실리케이트 복합체의 탄성률이 크게 증가 하여 나타나는 현상으로 해석할 수 있다. 물질에서 완전 점성체의 경우는 $\pi / 2$ 의 위상차를 가지고, 완전 탄성체의 경우는 0 의 위상차를 가지며 고분자와 같은 점탄성물질 의 경우는 탄성과 점성의 중간 위상차를 나타낸다. 
PP-SEBS/실리케이트 복합체의 위상차가 0 에 가깝게 나 타나는 것은 탄성 특성이 크기 때문으로 해석할 수 있다.

\section{4. 결론}

랜덤 $\mathrm{PP}$ 에 SEBS를 블렌드하고 실리케이트를 혼합하 여 PP-SEBS/실리케이트 복합체를 제조하고 특성을 평가 하였다. SEBS 함량이 증가할수록 용융온도는 감소하고 분해온도에는 큰 영향을 주지 않았다. PP-SEBS에 실리케 이트가 첨가되었을 때 용융온도는 $3^{\circ} \mathrm{C}$, 분해온도 $20^{\circ} \mathrm{C}$ 정 도의 증가를 보여주었다. PP-SEBS 블렌드에 실리케이트 가 첨가되면 shear thinning effect가 크게 증가하였고, 이 를 나타내는 power law index값이 PP40의 0.60 에서 PP40-S5의 0.37로 변화하였다. 용융장력에 영향을 주는 것으로 알려져 있는 탄성 특성 변화를 확인하기 위해 Van Gurp-Palmen 분석을 적용하였다. 분석결과 실리케 이트가 첨가된 경우 낮은 주파수 영역에서 위상차가 닞 은 값을 보여주었고, 이는 탄성특성의 증가를 나타내는 것이며, 실리케이트에 의한 고체특성이 고분자 용융체에 영향을 주어 나타나는 것으로 해석할 수 있다.

\section{참고문헌}

[1] 2008 Materials Roamap(Metal/Chemical/Fiber), Korea Industrial Technology Foundation, 783-1054, 2008.

[2] R. P. Lagendijk, A. H. Hogt, A. Buijtenhuijs, and A. D. Gotsis, "Peroxydicarbonate modification of polypropylene and extensional flow properties", Polymer, 42, 10035-10043, 2001.

[3] A. B. Lugao, B. W. H. Artel, A. Yoshiga, and H. Otaguro, "Production of high melt strength polypropylene by gamma irradiation", Radiation Phys. \& Chem., 76, 1691-1695, 2007.

[4] E. Borsig, M. van Duin, A. D. Gotsis, and F. Picchioni, "Long chain branching on linear polypropylene by solid state reactions", Euro. Polym. J., 44, 200-212, 2008.

[5] Y. C. Kim, "폴리프로필렌/옥수수전분 블렌드의 비등온 결정화 거동 연구", 한국산학기술학회논문, 9, 1125-1129, 2008.

[6] Y. C. Kim and J.-C. kim, "Study on the Silicate Dispersion and Rheological Properties of PP/StarchMB/Silicate Composites", J. Ind. Eng. Chem., 13, 1029-1034, 2007.

[7] H.-J. Kim, J.-C. Kim, J.-J. Lee, and Y. C. Kim, "Effect of starch content on the non-isothermal crystallization behavior of HDPE/silicate nanocomposites", J. Ind. Eng. Chem., 16, 406-410, 2010.

[8] D. J. Lohse, S. T. Milner, L. J. Fetters, and M. Xenidou, and M. K. Lyon, "Well-defined, model long chain branched polyethylene. 2. Melt rheological behavior", Macromolecules, 35, 3066-3075, 2002.

[9] M. Sugimoto, Y. Suzuki, K. Hyun, K. H. Ahn, T. Ushioda, T. Taniguchi, and K. Koyama, "Melt rheology of long-chain-branched polypropylenes", Rheol Acta, 46, 33-44, 2006.

[10] J.Z. Liang, "Effects of extrusion conditions on die-swell behavior of $\mathrm{PP} /$ diatomite composite melts", Polymer Testing, 27, 936-940. 2008.

[11] S. Tabatabaei, P. J. Carreau, and A. Ajji, "Rheological and thermal properties of blends of a long-chain branched polypropylene and different linear polypropylenes", Chemical Eng. Sci., 64, 4719-4731, 2009.

[12] F. Yu, H. Zhang, R. Liao, H. Zheng, W. Yu, and C. Zhou, "Flow induced crystallization of long chain branched polypropylenes under weak shear flow", Euro. Polym. J., 45, 2110-2118, 2009.

[13] S. li, M. Xiao, D. Wei, H. Xiao, F. Fu, and A. Zheng, "The melt grafting preparation and rheological characterization of long chain branching polypropylene", Polymer, 50, 6121-6128, 2009.

김 연 철(Youn Cheol Kim) [정회원]

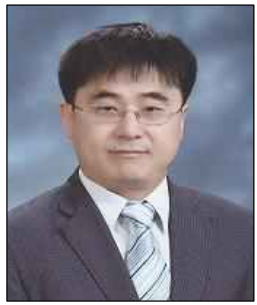

- 1994년 2월 : 한국과학기술원 화 학공학과 (공학박사)

- 1994년 2월 1996년 12월 : 삼 성종합화학연구소 선임연구원

- 1997년 7월 1998년 9월 : 일 리노이대학교 재료공학과 박사 후 연수

- 1999년 8월 현재 : 공주대학 교 고분자공학전공 교수

<관심분야>

고분자 구조 및 물성, 고분자 가공, 폴리올레핀 